\title{
Rancang Bangun Pemandu Tuna Netra Menggunakan Sensor Ultrasonik Berbasis Mikrokontroler
}

\author{
Muhammad Namiruddin Al-Hasan ${ }^{1}$, Cok Indra Partha ${ }^{2}$, Yoga Divayana ${ }^{3}$
}

\begin{abstract}
People with eye-disabilty have limited physical condition and make them using a stick as a tool guide for daily activities. Technology help people with eye-disabilty replace stick with tool guide using ultrasonic sensors to move more freely. Ultrasonic sensor works by using ultrasonic waves as a transmitter and calculate the distance using diffrence time lapse. Sensitivity of this sensor is from $2 \mathrm{~cm}$ to $200 \mathrm{~cm}$. Microcontoroller Arduino UNO can be used as data processing and vibrating motors as output. Tool guide for blind people use the belt as the main design. Sensors placed on the left side, front, and right belt to detect objects in front of sensors. Vibrating motors placed at the side of the sensor to provide vibration when the ultrasonic sensors active. Tool guides for blind people have specialized in detecting obstacle $30 \mathrm{~cm}$ in the left belt, $150 \mathrm{~cm}$ in front of the belt, $30 \mathrm{~cm}$ in right belt $30 \mathrm{~cm}$, and $120 \mathrm{~cm}-125 \mathrm{~cm}$ under the belt.
\end{abstract}

Intisari- Penyandang tuna netra memiliki kondisi fisik yang terbatas. Kondisi fisik ini membuat penyandang menggunakan tongkat sebagai alat pemandu dalam kegiatan sehari-hari. Kemajuan teknologi membantu penyandang mengganti tongkat dengan alat pemandu menggunakan sensor ultrasonik sehingga lebih leluasa bergerak. Sensor ultrasonik bekerja dengan memanfaatkan gelombang ultrasonik sebagai pemancar dan menghitung jarak dengan perbedaan selisih waktu. Kepekaan sensor ultrasonik dari $2 \mathrm{~cm}$ sampai $200 \mathrm{~cm}$. Pengolah data yang digunakan adalah mikrokontroler arduino dan keluaran berupa motor getar. Alat pemandu tuna netra menggunakan sabuk sebagai desain utama. Sensor diletakkan pada sisi kiri, depan, dan kanan sabuk untuk mendeteksi benda yang berada pada jarak pantulan sensor. Motor getar diletakkan pada samping sensor untuk memberikan getaran ketika sensor ultrasonik aktif. Alat pemandu tuna netra mempunyai spesifikasi dalam mendeteksi jarak $30 \mathrm{~cm}$ di kiri sabuk, $150 \mathrm{~cm}$ di depan sabuk, 30 cm di kanan sabuk dan $120 \mathrm{~cm}-125 \mathrm{~cm}$ di bawah sabuk.

Kata Kunci-sensor ultrasonik, Mikrokontroler Arduino, motor getar, jarak.

\section{PENDAHULUAN}

Tuna netra merupakan kondisi pada mata sehingga tidak berfungsi dengan baik. Penyandang tuna netra menggunakan tongkat sebagai penunjuk arah untuk mengetahui keadaan di sekitarnya. Menggunakan tongkat berarti kurangnya fleksibilitas bagi tuna netra. Diharapkan dengan adanya alat bantu sabuk pemandu tuna netra, penyandang bisa lebih leluasa bergerak.

\footnotetext{
${ }^{1}$ Mahasiswa Teknik Elektro, Tahunan UH III/310 Rt. 13 Rw. 03 YOGYAKARTA; e-mail: muhammad_namir@yahoo.com

${ }^{2,3}$ Dosen Teknik Elektro Fakultas TeknikUniversitasUdayana, Jln. Kampus Bukit Jimbaran 80361 INDONESIA (telp: 0361703315; fax:0361-4321; e-mail: cokindra@unud.ac.id, yogadivayana@gmail.com
}

Pada penelitian sebelumnya telah dibuat alat pemandu tuna netra menggunakan sensor ultrasonik berbasis mikrokontroler Arduino. Penelitian ini menggunakan tongkat pemandu sebagai melekatnya sensor sehingga pengguna dapat mengetahui benda di sekitarnya[1]. Akan tetapi dengan menggunakan tongkat sebagai melekatnya sensor, ruang gerak pengguna masih terbatas.

Penelitian kali ini menggunakan sabuk sebagai pengganti tongkat untuk memandu tuna netra. Alat yang dibuat menggunakan sensor ultrasonik sebagai input, data dikelola pada mikrokontroler Arduino dan keluarannya berupa getaran dihasilkan dari motor getar DC.

\section{KAJIAN PUSTAKA}

A. Penyandang Tuna netra

Tuna netra adalah kondisi dimana mata pada manusia tidak normal. Kondisi mata yang tidak normal adalah ketika benda yang ditangkap oleh mata tidak dapat diteruskan oleh kornea, lensa mata, retina dan ke syaraf. Hal seperti ini bisa disebabkan oleh beberapa hal seperti faktor keturunan, kecelakaan atau suatu penyakit. Penderita tuna netra untuk mempersepsikan suatu lingkunngannya menggunakan indera indera yang lain atau biasa menggunakan tongkat sebagai penunjuk arah.

B. Sensor Ultrasonik

Sensor Ultrasonik ialah sensor dengan prinsip kerja menggunakan pantulan gelombang untuk mengetaui jarak benda yang ada dalam frekuensianya. Sensor Ultrasonik menggunakan gelombang ultrasonic yang dapat merambat dalam medium padat, cair dan gas. Prinsip kerjanya yaitu pemancar gelombang akan mengirimkan sinyal kemudian diukur waktu yang dibutuhkan sampai pada datangnya pantulan objek[2].

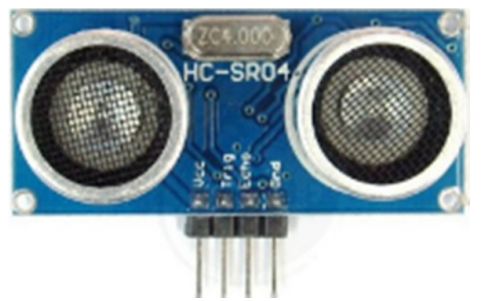

Gambar 1: Sensor ultrasonik

Sensor menggunakan sonar untuk menentukan jarak terhadap suatu objek[3]. Sensor yang digunakan berjumlah empat buah, yakni satu di depan, masing - masing di kanan dan kiri dan satu lagi di bagian bawah. Sensor pada bagian bawah sengaja ditambahkan untuk mempermudah pengguna apakah ada lubang dan bisa juga digunakan untuk menuruni tangga.

C. Mikrokontroler Arduino 
Mikrokontroler Arduino bersifat open source untuk pengendali mikro single board, sehingga memudahkan pengguna elektronik dalam berbagai bidang. Perangkat keras Arduino memiliki prosesor Atmel AVR yang bisa diprogram menggunakan komputer dan perangkat lunaknya memiliki bahasa pemograman IDE[4]. Tujuan menanamkan program supaya rangkaian elektronik dapat membaca input, memprosesnya kemudian menghasilkan output seperti yang diinginkan. Penelitian ini menggunakan mikrokontroler arduino sebagai pengolah data dari input berupa sensor ultrasonik. Pin yang digunakan adalah pin digital Input dan pada keluarannya menggunakan motor DC memakai pin digital Output.

\section{Motor getar DC}

Motor getar DC merupakan komponen elektronika yang berfungsi memberikan getaran sebagai output. Pada penelitian ini motor DC digunakan sebagai keluaran ketika sensor ultrasonik aktif. Jenis motor getar DC yang digunakan adalah 304-108 empat milimeter. Motor getar DC ini memiliki tegangan $3 \mathrm{~V}$, arus $90 \mathrm{~mA}$, beban inersia $100 \mathrm{~g}$, getaran Amplitudo 0,6 G dan tahanan insulasi $10 \mathrm{Mohm}[5]$.

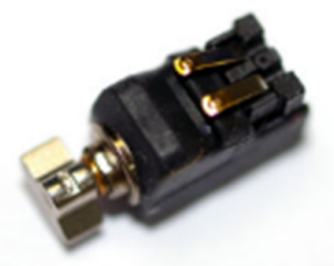

Gambar 2: Motor getar DC

\section{METODE PENELITIAN}

Perancangan diagram alir dari alat pemandu tuna netra menggunakan sensor ultrasonik digunakan sebagai pedoman langkah - langkah yang akan dilakukan dalam penelitian. Diagram alir penelitian ditunjukkan pada gambar 3 .

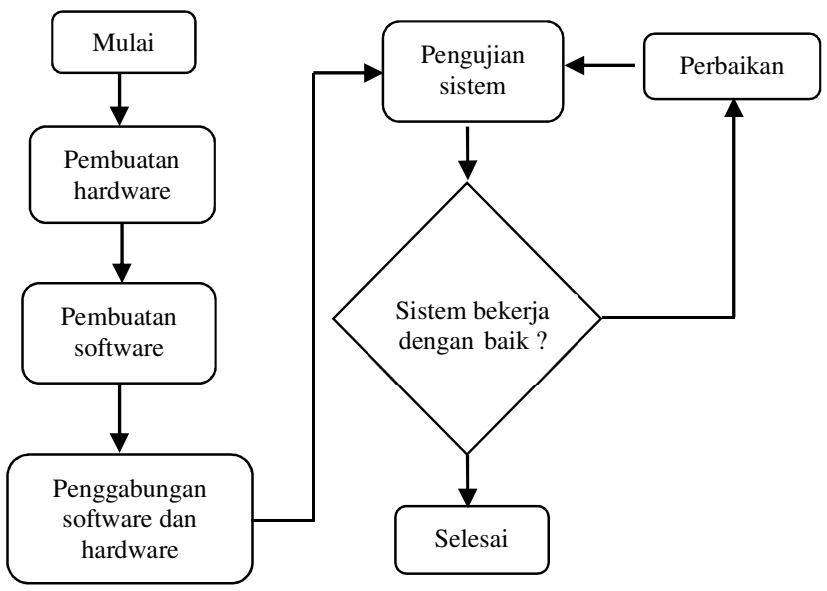

Gambar 3: Diagram alir penelitian alat pemandu tuna netra

A. Pembuatan hardware

Pembuatan perangkat keras pada alat pemandu tuna netra menggunakan sensor ultrasonik berbasis mikrokontroler arduino yaitu terdiri dari 4 bagian yaitu perancangan power suplay, perancangan rangkaian input sensor, perancangan rangkaian output sensor dan perancangan mikrokontroler sebagai pengolah data untuk input dan output. Pembuatan hardware keseluruhan dapat dilihat pada gambar 4.

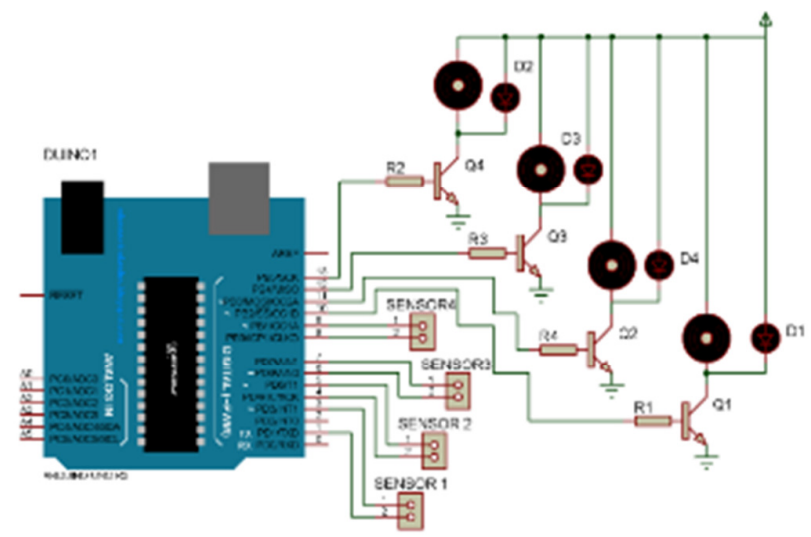

Gambar 4: Perancangan rangkaian hardware

B. Pembuatan software

Pembuatan perangkat lunak pada alat pemandu tuna netra menggunakan platfrom arduino IDE 1.6.9 yang sudah disediakan oleh manufaktur dan dapat di dwonload secara bebas melalui website arduino. Diagram alir dari alat pemandu tuna netra menggunakan sensor ultrasonik digunakan sebagai pedoman langkah - langkah yang akan dilakukan dalam pembuatan perangkat lunak ditunjukkan pada gambar 5 .

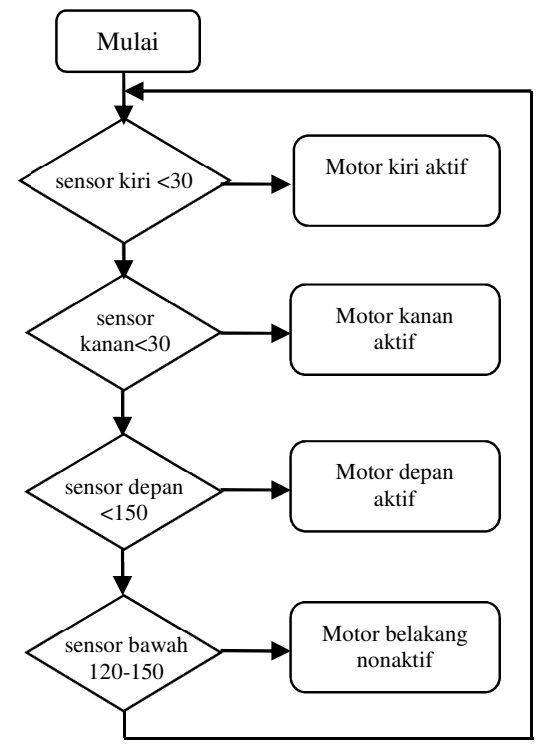

Gambar 5: Diagram alir pembuatan perangkat lunak

C. Gambaran umum perancangan sistem

Dalam melakukan perancangan sistem alat pemandu tuna netra dapat dilakukan dengan membuat desain dari alat tersebut menggunakan sabuk. Lingkungan dalam pengujian 

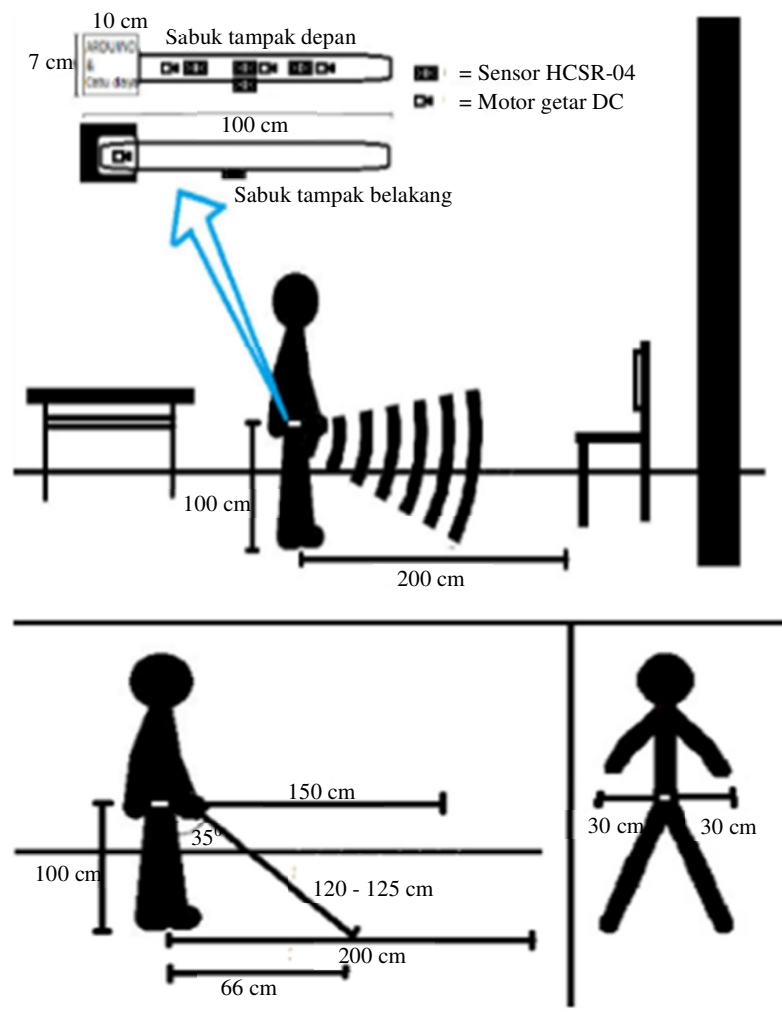

Gambar 6: Gambaran umum perancangan sistem

Penjelasan dari perancangan sistem pada gambar 6 yaitu, penyandang tuna netra menggunakan sabuk pada sebuah ruangan yang tedapat beberapa halangan seperti meja, kursi dan dinding. Sabuk yang digunakan terdapat empat sensor HCSR-04 dan motor getar DC dan kepala sabuk digunakan untuk meletakkan arduino UNO dan rangkaian power supply. Cara pemasangan sabuk terbalik, sehingga kepala sabuk berada di belakang pinggangdan tengah sabuk yang terdapat dua sensor berada di depan pinggang. Sabuk dipasang dengan ketinggian $100 \mathrm{~cm}$ dari kaki. Sensor ke empat yang berada didepan pinggan diarahkan ke bawah dengan sudut $35^{\circ}$ sehingga dapat mendeteksi halangan yang berada di bawah seperti tangga, tanjakan dan lubang. Sensor kiri dan kanan mendeteksi halangan ketika berjarak $30 \mathrm{~cm}$ dari pinggang penyandang tuna netra dan sonsor depan mendeteksi halangan ketika berjarak $150 \mathrm{~cm}$ dari pinggang penyandang tuna netra, sedangkan jarak maksimum yang dapat diukur oleh setiap masing-masing sensor adalah $200 \mathrm{~cm}$.

\section{HASIL DAN PEMBAHASAN}

\section{A. Realisasi Hasil Perancangan}

Realisasi perancangan alat pemandu tuna netra menggunakan sensor ultrasonik berbasis mikrokontroler ditunjukkan pada gambar 7 dan gambar 8. Pada gambar 7 menunjukkan alat pemandu tampak depan yang tediri dari motor kanan, sensor kanan, motor depan, sensor depan, sensor bawah, sensor kiri, motor kiri, arduino UNO dan power supply.

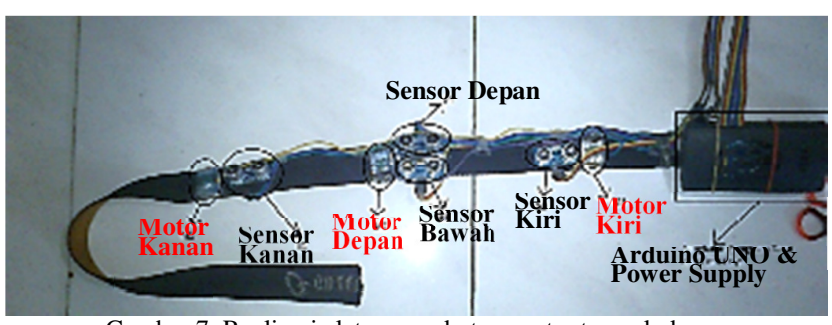

Gambar 7: Realisasi alat pemandu tuna netra tampak depan

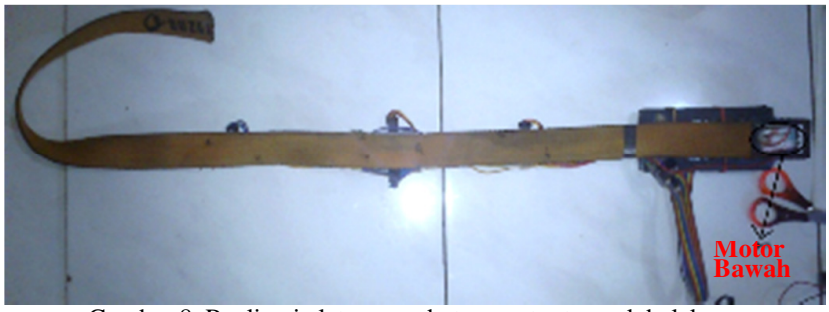

Gambar 8: Realisasi alat pemandu tuna netra tampak belakang

Gambar 8 menunjukkan alat pemandu tampak belakang terdapat motor bawah yang bekerja ketika sensor bawah aktif. Alat pemandu tuna netra mempunyai spesifikasi yang ditunjukkan pada tabel I.

TABEL I: SPESIFIKASI ALAT PEMANDU TUNA NETRA

\begin{tabular}{|l|l|l|}
\hline No & Spesifikasi & \multicolumn{1}{c|}{ Keterangan } \\
\hline 1 & Catu Daya & $9 \mathrm{~V}$ \\
\hline 2 & Masukan & 4 buah sensor ultrasonik HCSR-04 \\
\hline 3 & Keluaran & 4 buah motor getar DC \\
\hline 4 & Prosesor & Modul Arduino UNO \\
\hline 5 & Dimensi & $100 \mathrm{~cm} \mathrm{X} 7 \mathrm{~cm}$ \\
\hline
\end{tabular}

B. Pengujian rangkaian power supply

Pengujian rangkaian power supply dilakukan dengan merangkai power supply dan alat ke digital multi fungsi meter DC untuk menampilkan konsumsi daya yang diperlukan pada alat pemandu tuna netra seperti pada gambar 9 .

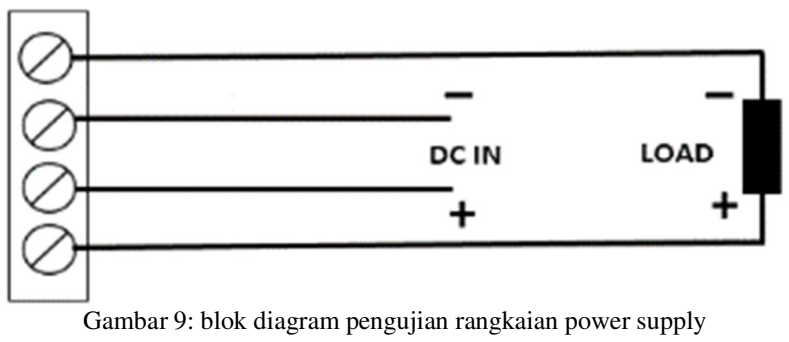

Keadaan siaga alat pemandu merupakan keadaan dimana rangkaian sensor dan rangkaian pengolah data bekerja tetapi belum memberikan keluaran ke rangkaian output. Dalam keadaan siaga ini konsumsi daya yang diperlukan alat pemandu ditunjukkan pada gambar 10(a). Keadaan beroperasi alat pemandu ditunjukkan ketika semua rangkaian bekerja. 
Konsumsi daya pada saat alat pemadu ketika keadaan beroperasi maksimal ditunjukkan pada gambar 10(b).

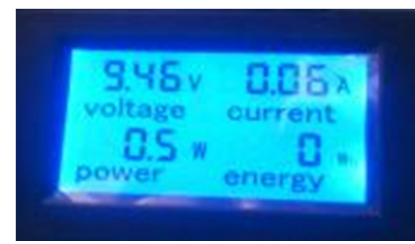

(a)

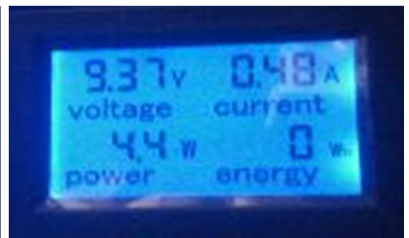

(b)

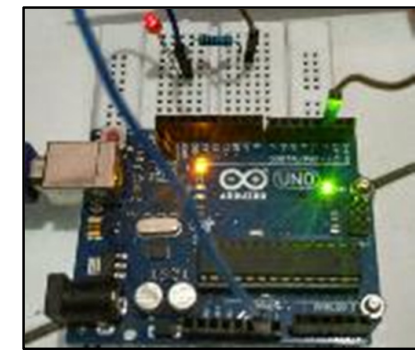

(a)

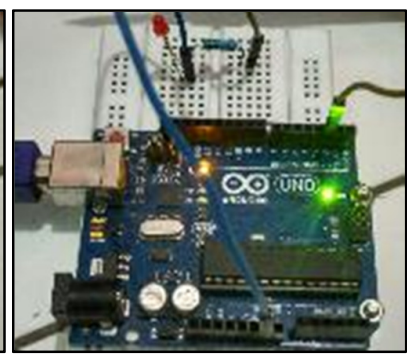

(b)
Gambar 12: rangkaian penguji pengolah data dengan LED (a) menyala (b) mati

\section{Pengujian rangkaian input}

Pengujian rangkaian input dapat dilakukan dengan memberikan program pada arduino dari komputer. Kemudian arduino dihubungkan ke input berupa sensor ultrasonik. Pada saat arduino dijalankan sensor akan bekerja mendeteksi halangan yang berada di depan dan membandingkannya dengan serial monitor yang berada di komputer. Pengujian rangkaian input ditunjukkan pada blok diagram gambar 13.

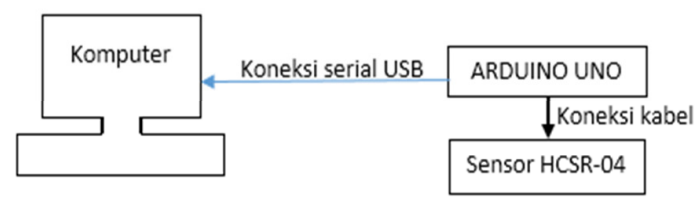

Gambar 13: blok diagram pengujian rangkaian input

Program untuk menguji rangkaian input menggunakan koding. Koding ini bertujuan untuk mendeteksi jarak halangan yang berada di depan sensor dari $2 \mathrm{~cm}$ sampai $200 \mathrm{~cm}$. Koding pengujian rangkaian input adalah sebagai berikut:

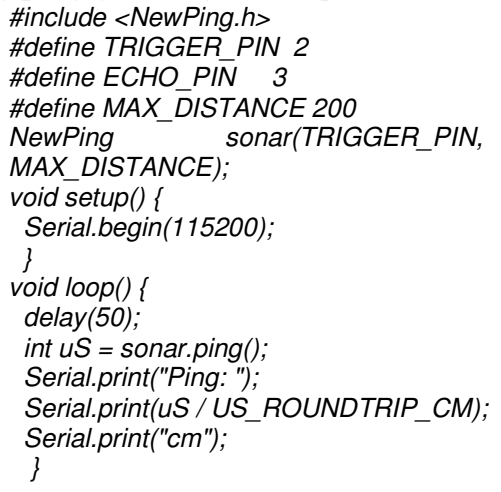

Hasil dari pengujian rangkaian input untuk pengukuran jarak yang sebenarnya dengan jarak yang dideteksi oleh serial monitor mempunyai perbedaan yang sedikit. Perbedaan antara hasil pengukuran dengan jarak yang sesungguhnya hanya 1 $\mathrm{cm}$ dan tidak mempengaruhi kinerja alat pemandu tuna netra, sehingga rangkaian input mempunyai ketelitian yang baik. Gambar 14(a) menunjukkan bahwa jarak yang sesungguhnya benda dengan sensor dan gambar 14 (b) menunjukkan jarak yang dideteksi melalui serial monitor. 


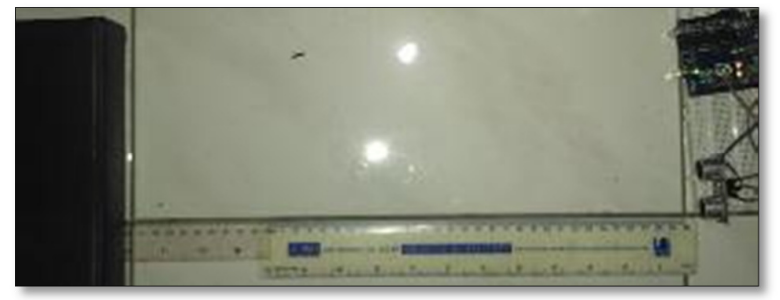

(a)

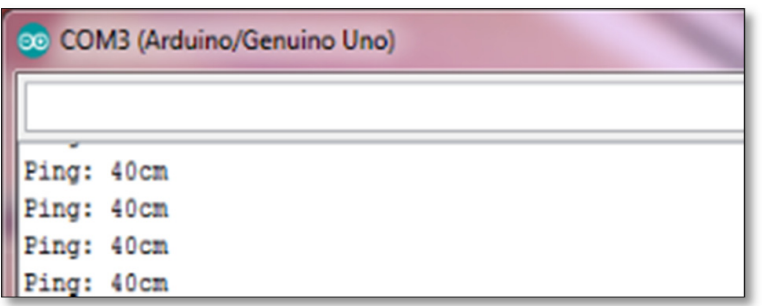

(b)

Gambar 14: Hasil pengujian rangkaian input (a) jarak yang sesungguhnya (b) jarak yang dideteksi oleh rangkaian

Rangkaian input terdiri dari empat sensor S1, S2, S3 dan S4. Pengujian rangkaian input pada setiap sensor mengambil 4 sampel jarak yaitu pada jarak $40 \mathrm{~cm}, 80 \mathrm{~cm}, 160 \mathrm{~cm}$, dan 200 $\mathrm{cm}$. Hasil pengukuran dari setiap sensor ultrasonik HC-SR04 ditunjukkan pada tabel III.

TABEL III: HASIL PENGUJIAN RANGKAIAN INPUT

\begin{tabular}{|c|c|c|c|c|c|}
\hline \multirow{2}{*}{ No } & Nama & \multicolumn{4}{|c|}{ Hasil Pengukuran } \\
\cline { 3 - 6 } & Sensor & $\mathbf{4 0} \mathbf{c m}$ & $\mathbf{8 0} \mathbf{c m}$ & $\mathbf{1 6 0} \mathbf{c m}$ & $\mathbf{2 0 0} \mathbf{c m}$ \\
\hline 1 & $\begin{array}{c}\text { Sensor } 1 \\
(\text { S1) }\end{array}$ & $40 \mathrm{~cm}$ & $80 \mathrm{~cm}$ & $161 \mathrm{~cm}$ & $199 \mathrm{~cm}$ \\
\hline 2 & $\begin{array}{c}\text { Sensor } 2 \\
(\text { S2) }\end{array}$ & $40 \mathrm{~cm}$ & $80 \mathrm{~cm}$ & $160 \mathrm{~cm}$ & $200 \mathrm{~cm}$ \\
\hline 3 & $\begin{array}{c}\text { Sensor } 3 \\
(\text { S3) }\end{array}$ & $40 \mathrm{~cm}$ & $80 \mathrm{~cm}$ & $160 \mathrm{~cm}$ & $200 \mathrm{~cm}$ \\
\hline 4 & $\begin{array}{c}\text { Sensor } 4 \\
(\text { S4) }\end{array}$ & $40 \mathrm{~cm}$ & $80 \mathrm{~cm}$ & $160 \mathrm{~cm}$ & $200 \mathrm{~cm}$ \\
\hline
\end{tabular}

\section{E. Pengujian rangkaian output}

Pengujian dilakukan dengan menghubungkan arduino ke motor getar DC dengan memberikan logika LOW dan HIGH pada arduino. Arus dan tegangan diukur menggunakan volt meter dan ampere meter ketika arduino diberi logika HIGH dan melihat motor getar DC(LOAD) aktif atau tidak. Blok diagram pengujian rangkaian output ditunjukkan melalu gambar 15 .

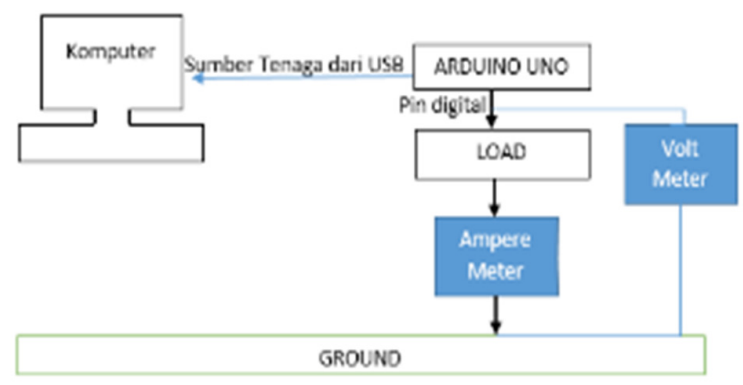

Gambar 15: Blok diagram rangkaian pengujian output

Hasil pengujian dari blok diagram pada gambar 14 yaitu tegangan yang terukur ketika arduino diberi logika HIGH adalah 4.7 Volt dan arus yang terukur ketika arduino diberi logika HIGH adalah 0.07 Ampere. Motor DC ketika diberi logika HIGH memberikan respon sehingga motor DC hidup. Hasil pengukuran tegangan dapat dilihat pada gambar 16(a) dan pengukuran arus dapat dilihat pada gambar 16(b).

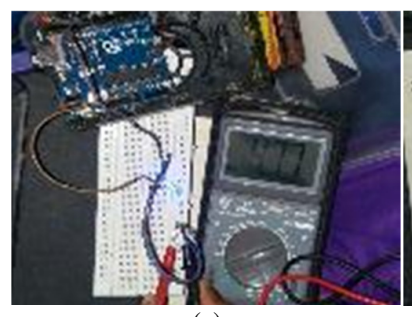

(a)

Gambar 16: Hasil pengukuran (a) tegangan (b) arus ketika rangkaian output diberi logika HIGH

Rangkaian output terdiri dari Motor getar DC dan driver motor berupa trasnsistor. Rangkaian ini berguna untuk memberikan getaran pada pengguna alat pemandu tuna netra agar mengerti jika terdapat halangan / benda disekitarnya. Hasil pengujian rangkaian output ketika diberi logika LOW dan HIGH ditunjukkan pada tabel IV.

TABEL III: HASIL PENGUJIAN RANGKAIAN INPUT

\begin{tabular}{|l|l|c|c|}
\hline \multirow{2}{*}{ No } & Nama Motor & \multicolumn{2}{|c|}{ Hasil Pengujian } \\
\cline { 3 - 4 } & & LOW & HIGH \\
\hline 1 & Motor 1 (M1) & Mati & Hidup \\
\hline 2 & Motor 2 (M2) & Mati & Hidup \\
\hline 3 & Motor 3 (M3) & Mati & Hidup \\
\hline 4 & Motor 4 (M4) & Mati & Hidup \\
\hline
\end{tabular}

\section{F. Pengujian sistem}

Pengujian sistem merupakan gabungan dari perangkat keras yang sudah diuji dan perangkat lunak berupa kode-kode yang telah dibuat melalui flowchart pada gambar 5. Alat pemadu tuna netra yang telah selesai digabungkan selanjutnya dipakai oleh pengguna dan melakukan pengujian di dalam ruangan untuk melihat kinerja alat pemandu tuna netra. Pengguna alat pemandu tuna netra akan berjalan-jalan dalam sebuah ruangan di laboratorium teknik elektro dan ketika alat mendeteksi adanya halangan maka motor DC akan bergetar untuk memberitahukan pengguna. Kemudian pengguna akan menghindari datangnya getaran agar tidak menabrak halangan atau benda yang sudah terdeteksi. Perangkat lunak memberikan spesifikasi pada alat pemandu dalam menentukan jarak benda yang terdeteksi sensor ultrasonik HC-SR04. Jarak yang terdeteksi untuk sensor bagian kiri dan kanan sabuk yaitu kurang atau sama dengan $30 \mathrm{~cm}$, sensor yang berada di bagian depan sabuk yaitu kurang atau sama dengan $150 \mathrm{~cm}$. Hasil dai pengujian ini terlihat pada gambar 17(a), 17(b), 17(c) dan $17(d)$. 


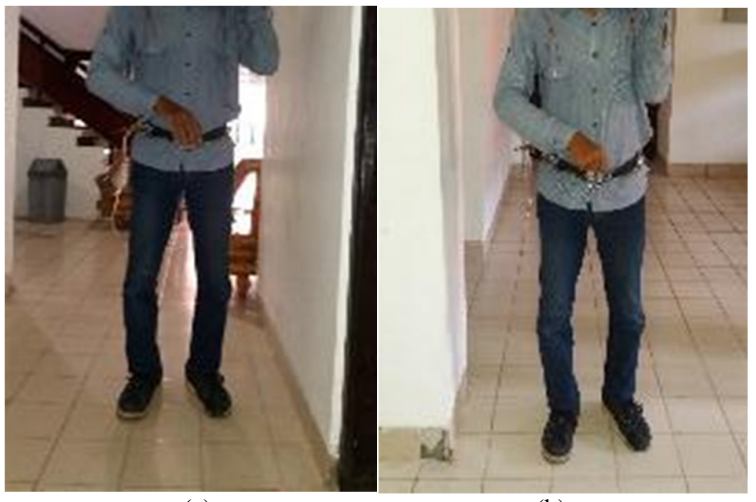

(a)

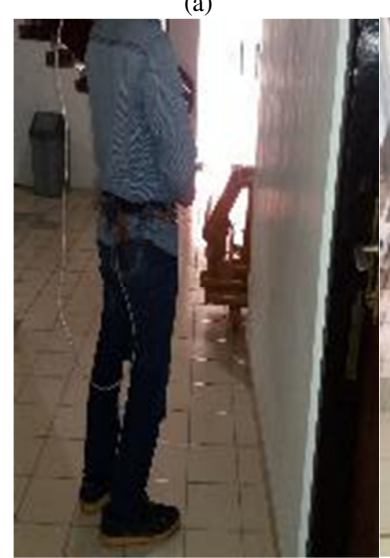

(c)

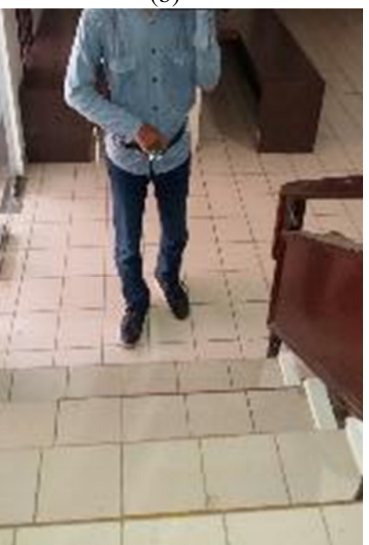

(d)

Gambar 17: Hasil pengujian sistem (a) kiri (b) kanan (c) depan (d) bawah pengguna

Gambar 17(a) menunjukkan pengujian sistem ketika mendeteksi halangan di kanan pengguna. Gambar 17(b) menunjukkan pengujian sistem ketika mendeteksi halangan di kiri pengguna. Gambar 17(c) menunjukkan pengujian sistem ketika mendetekksi halangan di depan pengguna. Gambar 17(d) menunjukkan pengujian sistem ketika mendeteksi halangan di bawah pengguna berupa tangga.

\section{KESIMPULAN}

Adapun simpulan yang dapat diambil dari hasil pengujian dan pembahasan yang telah dilakukan mengenai alat pemandu tuna netra menggunakan sensor ultrasonik berbasis mikrokontroler adalah sebagai berikut:

A. Alat pemandu tuna netra menggunakan sensor ultrasonik berbasis mikrokontroler dapat dibuat dengan baik menggunakan mikrontroler yang diletakkan pada sabuk sebagai desain inti dan mempunyai spesifikasi sebagai berikut:
a. Sensor S1 mempunyai spesifikasi mendeteksi halangan dari $1 \mathrm{~cm}-30 \mathrm{~cm}$.
b. Sensor S2 mempunyai spesifikasi mendeteksi halangan dari $1 \mathrm{~cm}-150 \mathrm{~cm}$.
c. Sensor S3 mempunyai spesifikasi mendeteksi halangan dari $1 \mathrm{~cm}-30 \mathrm{~cm}$.
d. Sensor S4 mempunyai spesifikasi mendeteksi halangan dari $120 \mathrm{~cm}-125 \mathrm{~cm}$.

B. Alat pemandu tuna netra menggunakan sensor ultrasonik berbasis mikrokontroler memiliki kinerja perangkat keras

Teknologi Elektro, Vol. 16, No.03,September-Desember 2017

yang baik dari pembacaan sensor ultrasonik HCSR - 04, pengolahan data arduino UNO, dan penentuan output motor getar sesuai jarak yang diberikan oleh program dari perangkat lunak arduino UNO.

\section{REFERENSI}

[1] Subandi. "Alat Bantu Mobilitas untuk tuna netra berbasis elektronik". Jurnal teknologi, volume 2 nomor 1 juni, 29-39.2009

[2] Budiharto, Widodo."10 Proyek Robot Spektakuler". Jakarta : Elex media komputindo.2015

[3] Arnawa, Sugiri. "Prototipe monitoring ketinggian air bendungan melalui media sosial twitter berbasis mikrokontroler Atmega-328pu". Teknologi elektro, vol. 14, No. 2, juli-desember, 2015

[4] Silvia, ai fitri. "Rancang bangun akses kontrol pintu gerbang berbasis arduino dan android". electrans,vol.13, no.1, hal. 1-10, maret, 2014

[5] " $4 \mathrm{~mm}$ vibration motor datasheet". Precision microdriver, England 